\title{
Citrus intake and risk of skin cancer in the European Prospective Investigation into Cancer and nutrition cohort (EPIC)
}

Yahya Mahamat-Saleh, $\mathrm{MPH}^{1,2}$, Iris Cervenka, MPH, $\mathrm{PhD}^{1,2}$, Marie Al-Rahmoun, $\mathrm{MPH}^{1,2}$, Francesca R. Mancini, MPH, $\mathrm{PhD}^{1,2}$, Gianluca Severi, $\mathrm{PhD}^{1,2}$, Reza Ghiasvand, $\mathrm{PhD}^{3}$, Marit. B Veierod, $\mathrm{PhD}^{3}$, Saverio Caini, $\mathrm{PhD}^{4}$, Domenico Palli, $\mathrm{MPH}, \mathrm{MD}^{4}$, Edoardo Botteri, $\mathrm{PhD}^{5.6}$, Carlotta Sacerdote, $\mathrm{PhD}^{7}$, Fulvio Ricceri, $\mathrm{PhD}^{8}$, Antonia Trichopoulou, $\mathrm{MD}, \mathrm{PhD}^{9}$, Eleni Peppa, PhD ${ }^{9}$, Carlo La Vecchia, MD, $\mathrm{PhD}^{9,10}$, Kim Overvad, MD, $\mathrm{PhD}^{11,12}$, Christina. C Dahm, PhD ${ }^{11}$, Anja Olsen, $\mathrm{PhD}^{13}$, Anne Tjønneland, MD, $\mathrm{PhD}^{13,14}$, Aurora Perez-Cornago, $\mathrm{PhD}^{15}$, Paula Jakszyn, $\mathrm{PhD}^{16,17}$, Sara Grioni, $\mathrm{PhD}^{18}$, Matthias B. Schulze, $\mathrm{PhD}^{19,20}$, Guri Skeie, $\mathrm{PhD}^{21}$, Cristina Lasheras, $\mathrm{PhD}^{22}$, Sandra Colorado-Yohar, MPH, $\mathrm{PhD}^{23,24,25}$, Miguel Rodríguez-Barranco, $\mathrm{PhD}^{24,26,27}$, Tilman Kühn, $\mathrm{PhD}^{28}$, Verena A. Katzke, $\mathrm{PhD}^{28}$, Pilar Amiano, $\mathrm{PhD}^{24,29}$, Rosario Tumino, $\mathrm{MD}, \mathrm{PhD}^{30}$, Salvatore Panico, $\mathrm{PhD}^{31}$, Ana Ezponda, $\mathrm{PhD}^{32}$, Emily Sonestedt, $\mathrm{PhD}^{33}$, Augustin Scalbert, $\mathrm{PhD}^{34}$, Elisabete Weiderpass, MD, MSc, $\mathrm{PhD}^{35}$, Marie-Christine Boutron-Ruault, $\mathrm{MD}, \mathrm{PhD}^{1,2}$, Marina Kvaskoff, $\mathrm{MPH}, \mathrm{PhD}^{1,2 *}$

\section{Affiliations of authors :}

1: CESP, Fac. de médecine - Univ. Paris-Sud, Fac. de médecine - UVSQ, INSERM, Université Paris Saclay, 94 805, Villejuif, France

2: Gustave Roussy, F-94805, Villejuif, France

3: Oslo Centre for Biostatistics and Epidemiology, Department of Biostatistics, Institute of Basic Medical Sciences, University of Oslo, Norway

4: Cancer Risk Factors and Lifestyle Epidemiology Unit, Cancer Research, Prevention and Clinical Network Institute (ISPRO), Florence, Italy

5: Department of Bowel Cancer Screening, Cancer Registry of Norway, Oslo University Hospital, Oslo, Norway.

6: Norwegian National Advisory Unit for Women's Health, Women's Clinic, Oslo University Hospital, Oslo, Norway

7: Piedmont Reference Centre for Epidemiology and Cancer Prevention (CPO Piemonte), Turin, 10126, Italy

8: Epidemiology Unit, ASL TO3 Piedmont Region, Grugliasco, 10095, Italy

9: Hellenic Health Foundation, Athens, Greece.

10: Department of Clinical Sciences and Community Health Università degli Studi di Milano, 
Itlay

11: Department of Public Health, Aarhus University, Aarhus, Denmark

12: Department of Cardiology, Aalborg University Hospital, Aalborg, Denmark

13: Danish Cancer Society Research Center, Copenhagen, Denmark

14: Department of Public Health, University of Copenhagen, Copenhagen, Denmark

15: Cancer Epidemiology Unit, Nuffield Department of Population Health, University of Oxford, Oxford, UK

16 : Unit of Nutrition and Cancer, Cancer Epidemiology Research Programme, Catalan Institute of Oncology, ĹHospitallet de Llobregat, Barcelona, Spain

17: Facultat de Ciències de la Salut Blanquerna, Universitat Ramón Llull, Barcelona, Spain.

18: Epidemiology and Prevention Unit, Fondazione IRCCS Istituto Nazionale dei Tumori, Milan, Italy.

19: Department of Molecular Epidemiology, German Institute of Human Nutrition PotsdamRehbruecke, Nuthetal, Germany

20: Institute of Nutritional Sciences, University of Potsdam, Nuthetal, Germany

21: Department of Community Medicine, University of Troms $\varnothing$, The Arctic University of Norway, Troms $\varnothing$, Norway

22: Department of Functional Biology, University of Oviedo, Asturias, Spain

23: Department of Epidemiology, Murcia Regional Health Council, IMIB-Arrixaca, Murcia, Spain.

24: CIBER Epidemiología y Salud Pública (CIBERESP), Spain.

25: Research Group on Demography and Health, National Faculty of Public Health,

University of Antioquia, Medellín, Colombia.

26: Andalusian School of Public Health (EASP). Granada, Spain.

27: Instituto de Investigación Biosanitaria de Granada (ibs.GRANADA). Universidad de

Granada. Granada, Spain

28: Division of Cancer Epidemiology, German Cancer Research Center (DKFZ), Heidelberg, Germany

29: Public Health Division of Gipuzkoa, BioDonostia Research Institue, Donostia-San Sebastian, Spain

30: Cancer Registry and Histopathology Department, Civic-M. P. Arezzo Hospital, ASP

Ragusa, Ragusa, Italy

31: Dipartimento di Medicina Clinica e Sperimentale, Federico II University, Naples, Italy

32: Clínica Universidad de Navarra, Pamplona, Spain 
33: Nutritional Epidemiology, Department of Clinical Sciences Malmö, Lund University, Malmö, Sweden

34: Biomarkers Group, International Agency for Research on Cancer, Lyon, France.

35: International Agency for Research on Cancer, World Health Organization, Lyon, France

*Corresponding author: Dr. Marina Kvaskoff, Inserm U1018, Health across Generations Team, Gustave Roussy, Espace Maurice Tubiana, 114 rue Edouard Vaillant, F-94805 Villejuif Cedex, France; Tel: +33 14211 5864; Fax: +33 14211 4000; Email: Marina.KVASKOFF@gustaveroussy.fr

Manuscript word count: Full text: 3327; abstract: 250

Running head: citrus and skin cancer risk

Abbreviations used: BCCs: basal-cell carcinomas; BMI: body mass index; CIs: confidence intervals; E3N: Etude Epidemiologique auprès de femmes de l'Education Nationale; EPIC: European Prospective Investigation into Cancer and Nutrition; HPFS: Health Professionals Follow-Up Study, HR: hazard ratio; IARC: International Agency for Research on Cancer; KCs: keratinocyte cancers; METs: metabolic equivalents of task; NHS: Nurses’ Health Study; PUVA: Psoralen and ultraviolet radiation A radiation; SCCs: squamous-cell carcinomas; SD: standard deviation; UV: ultraviolet radiation; 


\section{ABSTRACT}

Background: Citrus intake has been suggested to increase the risk of skin cancer. Although this relation is highly plausible biologically, epidemiologic evidence is lacking. We aimed to examine the potential association between citrus intake and skin cancer risk.

Methods: EPIC is an ongoing multi-center prospective cohort initiated in 1992 and involving 520,000 participants who have been followed-up in 23 centers from 10 European countries. Dietary data were collected at baseline using validated country-specific dietary questionnaires. We used Cox proportional hazards regression models to compute hazard ratios (HR) and 95\% confidence intervals (CI).

Results: During a mean follow-up of 13.7 years, 8,448 skin cancer cases were identified among 270,112 participants. We observed a positive linear dose-response relationship between total citrus intake and skin cancer risk $(\mathrm{HR}=1.10,95 \% \mathrm{CI}=1.03-1.18$ in the highest vs. lowest quartile; $\left.\mathrm{P}_{\text {trend }}=0.001\right)$, particularly with basal cell carcinoma $(\mathrm{BCC})(\mathrm{HR}=1.11$, $\left.95 \% \mathrm{CI}=1.02-1.20, \mathrm{P}_{\text {trend }}=0.007\right)$ and squamous cell carcinoma $(\mathrm{SCC}) \quad(\mathrm{HR}=1.23,95 \%$ $\left.\mathrm{CI}=1.04-1.47, \mathrm{P}_{\text {trend }}=0.01\right)$. Citrus fruit intake was positively associated with skin cancer risk $\left(\mathrm{HR}=1.08,95 \% \mathrm{CI}=1.01-1.16, \mathrm{P}_{\text {trend }}=0.01\right)$, particularly with melanoma $(\mathrm{HR}=1.23,95 \%$ $\mathrm{CI}=1.02-1.48 ; \mathrm{P}_{\text {trend }}=0.01$ ), although with no heterogeneity across skin cancer types $\left(\mathrm{P}_{\text {homogeneity }}=0.21\right)$. Citrus juice was positively associated with skin cancer risk $\left(\mathrm{P}_{\text {trend }}=0.004\right)$, particularly with BCC ( $\left.\mathrm{P}_{\text {trend }}=0.008\right)$ and $\mathrm{SCC}\left(\mathrm{P}_{\text {trend }}=0.004\right)$, but not with melanoma $\left(\mathrm{P}_{\text {homogeneity }}=0.02\right)$.

Conclusions: Our study suggests moderate positive linear dose-response relationships between citrus intake and skin cancer risk. Studies with available biomarker data and the ability to examine sun exposure behaviors are warranted to clarify these associations and examine the phototoxicity mechanisms of furocoumarin-rich foods.

Keywords: citrus; cohort studies; cutaneous melanoma; epidemiology; keratinocyte cancers;

\section{Conflict of interest}

The authors have no conflict of interest to disclose. 


\section{IARC disclaimer}

Where authors are identified as personnel of the International Agency for Research on Cancer / World Health Organization, the authors alone are responsible for the views expressed in this article and they do not necessarily represent the decisions, policy or views of the International Agency for Research on Cancer / World Health Organization.

\section{Funding}

Yahya Mahamat-Saleh was supported by a research scholarship from the Paris Ile-de-France region. The coordination of EPIC is financially supported by the European Commission (DGSANCO); and the International Agency for Research on Cancer. The national cohorts are supported by Danish Cancer Society (Denmark); the French National Institute of Health and Medical Research (Inserm), the Mutuelle Générale de 1'Education Nationale, the Gustave Roussy Institute, and the French League against Cancer (France); Deutsche Krebshilfe, Deutsches Krebsforschungszentrum (DKFZ); and Federal Ministry of Education and Research (Germany); Stavros Niarchos Foundation; the Hellenic Health Foundation; and Ministry of Health and Social Solidarity (Greece); Italian Association for Research on Cancer (AIRC); National Research Council; and AIRE-ONLUS Ragusa, AVIS Ragusa, Sicilian Government (Italy); Dutch Ministry of Public Health, Welfare and Sports (VWS); Netherlands Cancer Registry (NKR); LK Research Funds; Dutch Prevention Funds; Dutch ZON (Zorg Onderzoek Nederland); World Cancer Research Fund (WCRF); the National Institute for Public Health and the Environment (RIVM) and Statistics Netherlands (the Netherlands); European Research Council (ERC) (grant number ERC-2009-AdG 232997) and Nordforsk; and Nordic Center of Excellence Programme on Food, Nutrition and Health (Norway); Health Research Fund (FIS); Regional Governments of Andalucía, Asturias, Basque Country, Murcia (No. 6236) and Navarra; and ISCIII RETIC (RD06/0020) and the Catalan Institute of Oncology (Spain); Swedish Cancer Society; Swedish Scientific Council; and Regional Government of Skåne and Västerbotten (Sweden); Cancer Research UK (14136 to EPIC-Norfolk; C570/A16491 and C8221/A19170 for EPIC-Oxford); Medical Research Council (1000143 to EPIC-Norfolk, MR/M012190/1 to EPIC-Oxford); Stroke Association; British Heart Foundation; Department of Health; Food Standards Agency; and Wellcome Trust (UK). Reza Ghiasvand was supported by a grant (project 6823329) from the Norwegian Cancer Society. 


\section{INTRODUCTION}

Evidence suggests a potential association between citrus intake and skin cancer risk. Two large prospective cohort studies reported positive dose-response relationships between citrus consumption and the risks of cutaneous melanoma [1] and keratinocyte cancers (KC, including basal-cell (BCCs) and squamous-cell carcinomas (SCCs)) [2], in women from the Nurses' Health Study (NHS) and men from the Health Professionals Follow-Up Study (HPFS), respectively. In addition, recently, a large prospective cohort study of postmenopausal women suggested a positive association between citrus juice intake and melanoma risk [3]. These associations are highly plausible biologically [4-6], since citrus products are rich in furocoumarins such as psolarens [7], which exhibit carcinogenic and phototoxic effects [8]. Higher intake of total furocoumarins has indeed been reported to be associated with an increased risk of skin cancer, particularly of KCs, in the NHS and HPFS cohorts [9]. Oral administration of psoralen (methoxsalen) and UVA radiation (PUVA) has been used for many years to treat psoriasis and other skin diseases [10], and both experimental and epidemiologic studies suggested that long-term PUVA therapy increases skin cancer risk [11-13]. It has also been shown that psoralens and furocoumarins can interact with UV light to stimulate the proliferation of melanoma cells [14]. However, epidemiologic data showing an association are lacking.

Given the photosensitizing potential of furocoumarins and their known effects on skin, and given the intriguing associations described between citrus intake and skin cancer risk recently, a better understanding of the relationship between furocoumarin-rich foods and skin cancer risk is requested [4-6]. We sought to evaluate the associations between citrus consumption and skin cancer risk in the European Prospective Investigation into Cancer and Nutrition (EPIC) cohort study [15].

\section{METHODS}

\section{$\underline{\text { The EPIC cohort }}$}

EPIC is a multi-center prospective cohort study initiated in 1992. The rationale, full methods, and study design have been described in detail elsewhere [16]. Briefly, 521,448 participants mostly aged 25-70 years were recruited in 23 centers from 10 European countries (France, 
Italy, Spain, The Netherlands, United Kingdom, Greece, Germany, Sweden, Norway, and Denmark) between 1992 and 2000 [15,16]. All participants gave written informed consent, and approval for the study was obtained from local ethical committees in participating countries and from the International Agency for Research on Cancer review board.

\section{Dietary intakes}

At baseline, dietary intakes over the 12 months before recruitment were assessed using validated country-specific dietary questionnaires designed to reflect local dietary patterns [17]. In the present study, the analyzed food groups were citrus fruits and citrus juices; these groups were analyzed overall, as no information on type of citrus fruit or juice was available in the cohort. Total intake of citrus was calculated as the sum of intakes of citrus fruits and juices, excluding centers in which no data were available on citrus juice intake (France, UK, and Norway). Detailed information on other lifestyle factors was collected using genderspecific questionnaires common to all study centers [18].

\section{$\underline{\text { Follow-up and identification of cancer cases }}$}

Incident of cancer cases were identified through several methods, including record linkage with population-based cancer registries, health insurance records, pathology registries, and active follow-up of study subjects. Mortality data were obtained from cancer or mortality registries at the regional or national level. Skin cancer events were mostly ascertained through population-based cancer registries or pathology reports (96\% of cases; melanoma: $92 \%$; BCC: $96 \%$; SCC: $99 \%$ ), and a small proportion (4\%) was identified from hospital admission and discharge records or national/regional mortality registries. Registration of KC cases may be incomplete in some centers because these cancers are not systematically recorded in cancer registries. Follow-up began on the date of recruitment and ended on the date of skin cancer diagnosis, date of death, date of emigration/loss of follow-up, or date of completion of the last returned questionnaire, whichever came first. Cancer incidence data were coded according to the International Classification of Diseases for Oncology (ICD-O-3). Cancer cases were defined as subjects with a first primary incident skin cancer (including KCs; C44). Information on stage, site, morphology, and grade of melanoma was collected from each center, where possible. 


\section{Study sample}

Of the 521,448 participants, we first excluded prevalent cancer cases (including KCs) or subjects with missing information on date of diagnosis and follow-up information $(n=29,456)$, and those with missing information on lifestyle factors $(n=6,259)$ or extreme energy intake values $\left(<1^{\text {st }}\right.$ and $>99^{\text {th }}$ percentiles of the distribution) $(n=9,573)$. Because citrus consumption was our main exposure, and in order to conduct separate analyses for citrus fruit and juice and mutually adjust the models, we further excluded participants from the centers with no data on both citrus fruit and juice consumption $(n=206,048$ including participants from France $(n=67,403)$, the UK $(n=75,416)$, Norway $(n=33,975)$, Naples $(n=4,953)$, and Umea $(n=24,301))$, leaving a final sample of 270,112 participants for analysis.

\section{$\underline{\text { Statistical analysis }}$}

Statistical analyses were performed using the SAS package (version 9.4, SAS Institute). All significance tests were two-sided, $\mathrm{p}<0.05$ being considered statistically significant. Hazard Ratios (HRs) and 95\% confidence intervals (CIs) of the risks of overall skin cancer, melanoma, BCC, and SCC associated with citrus intake were estimated using Cox proportional hazards regression models with age as the time scale. We first evaluated associations between total citrus intake and skin cancer risk, and then assessed the association with citrus fruit and citrus juice intakes separately. Citrus intake was estimated in grams per day and divided into quartiles. Tests for linear trend were performed by modeling quartiles of intake as a continuous variable. Multivariable analyses were performed with adjustment for potential confounders such as lifestyle and dietary factors, which were selected based on previously published data [1,2,19]. Models were first adjusted for age and stratified by study center, sex, and age at recruitment (Model 1), then additionally adjusted for body mass index, smoking status, alcohol intake at baseline, physical activity level [18], and total energy intake (Model 2). A third model additionally included intakes of total vegetables, non-citrus fruits and juices, and coffee intake for total citrus (Model 3). This model then included different factors according to the type of citrus exposure: based on Model 2, analyses on citrus fruit were additionally adjusted for intakes of total vegetables, non-citrus fruits, citrus juice, and coffee. Again based on Model 2, analyses on citrus juice were additionally adjusted for 
intakes of total vegetables, citrus fruit, non-citrus juice, and coffee. When data on categorical covariates were missing, a 'missing' category was introduced in the model.

Since the consumption of citrus products differs across European countries, we conducted stratified analyses by country, using country-specific tertiles of intake. However, we checked that using tertiles of intake in the overall population for each exposure did not change our findings (data not shown). The analyses were also stratified according to sex. Using hours of recreational outdoor physical activity (combining physical exercise, walking, cycling, and gardening) in summer as a proxy for hours of recreational sun exposure, we evaluated potential effect modification by this factor using Wald tests. We further assessed the associations by tumor site and, for melanoma, histologic subtype, using competing-risk modeling, excluding cases with missing information on tumor characteristics for these analyses. Homogeneity tests were performed using Wald chi-square tests to compare estimates over tumor sites and types. Sensitivity analyses were carried out for the association between citrus fruit and skin cancer risk by including all study participants back in the analysis (including those from centers with no available data on citrus juice intake).

\section{RESULTS}

During a mean follow-up of 13.7 years, 8,448 skin cancer cases (melanoma: $n=1,371$; BCC: $\mathrm{n}=5,604$; SCC: $\mathrm{n}=1,165$, unknown type: $\mathrm{n}=306$ ) were identified among 270,112 participants. The mean intake of total citrus in the cohort was $90.9 \mathrm{~g} /$ day. Intakes varied across study locations, with the highest intakes observed in southern European countries (Spain, Italy, and Greece) and the lowest in Denmark (Table 1). Participants with high intakes of citrus were generally younger and more likely to be women, to have higher education and physical activity levels, and higher intakes of total energy, vegetables, non-citrus fruits, and non-citrus juices than those with low citrus intakes; however, they were less likely to be smokers and to consume alcohol and coffee (Table 2).

Total citrus intake was positively associated with skin cancer risk $(\mathrm{HR}=1.10,95 \% \mathrm{CI}=1.03-$ 1.18 for the highest quartile vs. the lowest, $\left.\mathrm{P}_{\text {trend }}=0.001\right)$, particularly with $\mathrm{BCC}(\mathrm{HR}=1.11$, 95\%CI=1.02-1.20, $\left.\mathrm{P}_{\text {trend }}=0.007\right)$ and SCC $\left(\mathrm{HR}=1.23,95 \% \mathrm{CI}=1.04-1.47, \mathrm{P}_{\text {trend }}=0.01\right) . \mathrm{We}$ found no association with melanoma $\left(\mathrm{HR}=0.98,95 \% \mathrm{CI}=0.83-1.15, \mathrm{P}_{\text {trend }}=0.96\right)$, although there was no heterogeneity across skin cancer types $\left(P_{\text {homogeneity }}=0.14\right)$ (Table 3). 
When performing separate analyses for citrus fruit and juice, we found that citrus fruit intake was positively and linearly associated with skin cancer risk $(\mathrm{HR}=1.08,95 \% \mathrm{CI}=1.01-1.16$ for the highest quartile vs. the lowest, $\left.\mathrm{P}_{\text {trend }}=0.01\right)$, particularly with melanoma $(\mathrm{HR}=1.23$, 95\%CI=1.02-1.48, $\mathrm{P}_{\text {trend }}=0.01$ ) (Table 4). However, while we found positively linear associations with BCC and SCC in the age-adjusted model, associations were no longer statistically significant after adjustment, again with no heterogeneity across cancer types $\left(\mathrm{P}_{\text {homogeneity }}=0.21\right)$, although statistical significance remained in the fourth quartile of intake for SCC. Citrus juice intake was positively and linearly associated with skin cancer risk $\left(\mathrm{HR}=1.08,95 \% \mathrm{CI}=1.01-1.16\right.$ for the highest quartile vs. the lowest, $\left.\mathrm{P}_{\text {trend }}=0.004\right)$, particularly with BCC $\left(\mathrm{HR}=1.10,95 \% \mathrm{CI}=1.01-1.19, \mathrm{P}_{\text {trend }}=0.008\right)$ and $\mathrm{SCC}(\mathrm{HR}=1.23,95 \% \mathrm{CI}=1.05-$ 1.44, $\left.\mathrm{P}_{\text {trend }}=0.004\right)$, but not with melanoma $\left(\mathrm{HR}=0.92,95 \% \mathrm{CI}=0.78-1.08, \mathrm{P}_{\text {trend }}=0.31\right)$ $\left(\mathrm{P}_{\text {homogeneity }}=0.02\right)$ (Table 5). These results were not substantially different after adjustment for hours of recreational sun exposure during outdoor physical activity in summer (data not shown).

We found no evidence for effect modification by lifestyle factors on the associations between citrus intake and skin cancer risk (Supplementary Table S1), and no evidence for heterogeneity across countries (Supplementary Table S2) or sexes (Supplementary Table S3). In site-specific analyses, the positive associations between total citrus or citrus fruit intake and BCC risk were stronger for trunk tumors vs. those of the head, neck, and extremities ( $\mathrm{P}_{\text {homogeneity }}=0.04$ and 0.02, respectively) (Supplementary Table S4); however, we detected no heterogeneity across sites for melanoma and SCC, or in subtype-specific analyses (Supplementary Table S5).

When participants from centers with no available data on citrus juice intake were included back in the analysis (total study sample: $n=476,160$ ), associations between citrus fruit intake and the risks of total skin cancer, BCC or SCC remained, although slightly reduced (Supplementary Table S6). However, a positive association with melanoma risk was no longer observed.

\section{DISCUSSION}


In this large European prospective study, we found a modest positive relationship between total citrus intake and skin cancer risk. Specifically, high intakes of citrus fruit were associated with higher melanoma risk, while citrus juice intake was positively and linearly associated with BCC and SCC risks.

To date, only three US prospective cohort studies explored the associations between citrus intake and skin cancer risk [1-3]. In the NHS and HPFS cohorts, higher intakes of citrus were associated with higher skin cancer risk [1,2]; specifically, participants who consumed citrus over 1.6 times per day had 36\%, 16\%, and $21 \%$ higher risks of melanoma, BCC, and SCC, respectively, compared with those who consumed citrus less than twice per week. Consistently, our findings suggested that higher intakes of citrus (i.e. the fourth (mean=217.5 $\mathrm{g} /$ day) vs. the first (mean=10.8 g/day) quartile of consumption) were associated with $11 \%$ and $23 \%$ higher risks of BCC and SCC, respectively. However, we did not find an association with melanoma risk, although with no detected heterogeneity across cancer types, which is consistent with the results from the Women Health Initiative (WHI) that reported no association between total citrus intake and melanoma risk after adjustment for known skin cancer risk factors [3]. Nevertheless, we observed that participants in the highest quartile of citrus fruit intake (mean=147.5 g/day) had a $23 \%$ increased melanoma risk compared with those in the first (mean=4.4 g/day), with a positive linear trend. There was also a positive association between citrus fruit intake and SCC risk but not BCC risk. In contrast, while citrus juice intake was not associated with melanoma risk, we found positive and linear associations with BCC and SCC risks. Unfortunately, we were unable to examine associations by type of citrus fruit or juice, since this information was not available in the EPIC cohort. However, in the NHS and HPFS cohorts, associations were restricted to grapefruit for citrus fruit, and to orange juice for citrus juice [1,2]. In contrast with our findings, the WHI study reported nonsignificant inverse association between citrus fruit intake and melanoma risk among postmenopausal women [3]. An Italian hospital-based case-control study also reported an inverse association between citrus fruit consumption and melanoma risk among 304 cases and 305 controls [20]; however, diet was assessed retrospectively in that study and thus subject to recall bias.

The three previous prospective studies suggested a possible interaction by UV exposure on these associations [1,2]. Although we observed no interaction between citrus intake and hours of summer recreational outdoor physical activity (which we used as a proxy for recreational 
sun exposure) in our analysis, the association appeared to be stronger for SCC among participants with higher levels of this variable. While this proxy incompletely reflects sun exposure, our findings lend support to those from the NHS and HPFS cohorts, which suggested that the positive associations between citrus intake and melanoma and SCC were stronger among participants with higher chronic sun exposure, those with a higher susceptibility to sunburn during childhood/adolescence, those with higher numbers of blistering sunburns, and those with higher annual residential UV flux. Also, our findings support those from the WHI study, in which an increased melanoma risk was observed in relation to citrus juice intake only among women who spent the most time outdoors in summer.

Citrus products are widely consumed foods; the major citrus fruits consumed in Europe are oranges, followed by clementines/tangerines, grapefruit, and lemons [21]. A potential mechanism underlying the observed associations could be based on the presence in citrus of psoralens and furocoumarins, a well-known class of photosensitizers with potential photocarcinogenic properties [22,23]. Indeed, the NHS and HPFS cohorts have recently confirmed that participants with a high intake of total furocoumarins had higher risks of skin cancer, particularly of KCs [9]. Specifically, higher intakes of bergaptol, bergapten, 6', 7'dihydroxybergamottin, and bergamottin were also significantly associated with increased KC risk. Furocoumarins are found naturally in the fruit peel, roots, and leaves of citrus products. Average estimated intakes of furocoumarins in the US and Germany are of 1.3 and $0.6 \mathrm{mg}$ per day, respectively, and grapefruit is estimated to contribute to around $73 \%$ of furocoumarin intake from foods in the Western diet $[24,25]$. Animal studies suggested that psoralen in the presence of UVA is mutagenic for the skin [26], and numerous observational studies have reported an increased risk of skin cancers in PUVA-treated psoriasis patients, including KCs and melanoma $[11,27,28]$. Clinical studies also indicate an increased risk of melanoma and KCs among patients treated with PUVA compared with the general population $[11,29]$. Orallyingested furocoumarins are well absorbed in the gastrointestinal tract and quickly transported in blood to numerous tissues including the skin [30,31], with a concentration peak in these tissues at 2-4 hours after consumption [32]. In the blood, furocoumarins can be distributed into multiple tissue types and allow DNA replication with damage, leading to carcinogenesis and the formation of skin tumors at high doses [33]. While DNA is the major target for psoralen action, leading to the stimulation of skin cell proliferation, psolarens may also bind to other specific and high-affinity sites in mammalian cells, which may modulate furocoumarin- 
induced phototoxicity [34]. Thus, a positive association between citrus intake and skin cancer risk that is heightened by UV exposure, as suggested by findings from the NHS, HPFS, WHI and this cohort, is highly plausible. Another hypothesis to explain the positive association between citrus fruit and melanoma risk is related to the potential contamination of citrus by pesticides. Previous research reported the presence of various pesticides in citrus fruits [35] and a positive association between several pesticides and melanoma risk [36].

Nevertheless, citrus products are also known to have antioxidant effects that could protect DNA against oxidative damage, regulate cell growth, and induce apoptosis [37]. They are also a significant source of vitamin $\mathrm{C}$, and vitamin C-rich foods were suggested to protect against cancer risk [38]. Moreover, while citrus intake was positively associated with skin cancer risk in our study, citrus intakes were inversely associated with non-skin cancers (lung [39], gastric $[29,30]$, prostate [40], and thyroid cancers [41]) in EPIC. However, citrus consumption was not associated with the risk of major non-skin cancers (breast, prostate, lung, and colorectal cancers) in the NHS/HPFS cohorts [1,2].

In our study, when participants from centers with no available data on citrus juice intake were included back in the analysis, we no longer observed an association between citrus fruit and melanoma, although associations remained for other outcomes. Patterns of citrus fruit consumption differ across European countries, and it is possible that melanoma risk is more strongly associated with some types of citrus fruit, as suggested by the NHS/HPFS analyses in which associations were restricted to grapefruit [1,2]. It could be hypothesized that grapefruit consumption was less frequent in these centers. In addition, the processes undertaken by the agricultural and food industries, which may differ across European countries, may also influence furocoumarin contents in citrus $[31,42,43]$. However, since data on type of citrus fruit were not available, we were unable to clarify the origin of this divergent result. Additional research is requested in different countries with detailed data on type of citrus fruit and juice to increase our understanding of these associations.

The main limitation of our study was the lack of information on recreational UV exposure; we cannot rule out residual confounding by this factor, since stratification by study center or adjustment for outdoor recreational physical activity may not have sufficiently attenuated this limitation. In addition, we lacked data on other skin cancer risk factors, such as pigmentary traits or family history of skin cancer. Moreover, combining data from different centers 
increased statistical power, but also may have resulted in heterogeneity because of differences in study population characteristics. However, we found no evidence for heterogeneity across countries for these associations. Furthermore, information on type of citrus was not available in EPIC; therefore we were not able to examine associations by citrus type. However, exposure to furanocoumarins in a Western diet was reported to primarily come from grapefruit juice [44], and grapefruit and orange juice intakes showed the strongest associations with melanoma, BCC, and SCC risks in the NHS and HPFS. In addition, dietary intakes and confounding factors were self-reported and some degree of misclassification cannot be excluded. However, such misclassification is likely to be non-differential, which would most likely result in an underestimation of the associations. In EPIC, diet was evaluated through a single dietary assessment at recruitment, which did not allow to take into account potential dietary changes during follow-up. Also, while skin cancer cases were ascertained with high confirmation rates, $\mathrm{KCs}$ are often not systematically recorded in cancer registries; thus, underestimation of the incidence of these cancers in some centers is likely. Despite these limitations, our study has several strengths, including its prospective design, particularly large study population and long duration of follow-up, and the fact that it spans a large number of European countries with a high variety of dietary profiles. In addition, dietary intake was assessed using validated dietary questionnaires in all centers.

In conclusion, our findings suggest modest positive linear relationships between citrus intake and skin cancer risk, which were mostly driven by associations with BCC and SCC. While high citrus fruit intakes were associated with melanoma risk, citrus juice intake was positively and linearly associated with BCC and SCC risks. Although additional studies are needed because of limited data on UV exposure and type of citrus fruit and juice in this analysis, the current findings lend support to previous research. Further studies with biomarker data, availability of detailed data on type of citrus, and the ability to examine UV exposure behaviors are warranted to clarify these associations and to examine the phototoxicity mechanisms of furocoumarin-rich foods.

\section{Acknowledgments}

We thank all study participants for their cooperation and all interviewers who participated in the fieldwork studies in each EPIC center. We also thank Bertrand Hemon at IARC for his valuable work and technical support with the EPIC database. 


\section{Reference}

1. Wu S, Han J, Feskanich D, Cho E, Stampfer MJ, Willett WC, et al. Citrus Consumption and Risk of Cutaneous Malignant Melanoma. J Clin Oncol. 2015;33:2500-8.

2. Wu S, Cho E, Feskanich D, Li W-Q, Sun Q, Han J, et al. Citrus consumption and risk of basal cell carcinoma and squamous cell carcinoma of the skin. Carcinogenesis. 2015;36:1162-8.

3. Melough MM, Wu S, Li W-Q, Eaton C, Nan H, Snetselaar L, et al. Citrus Consumption and Risk of Cutaneous Malignant Melanoma in the Women's Health Initiative. Nutr Cancer. 2020;72:568-75.

4. Dowdy JC, Sayre RM. Melanoma Risk From Dietary Furocoumarins: How Much More Evidence Is Required? J Clin Oncol. 2016;34:636-7.

5. Lehrer S, Green S, Rosenzweig KE. Melanoma Risk and Citrus Consumption. J Clin Oncol. 2016;34:636.

6. Wu S, Cho E, Qureshi AA. Reply to S. Lehrer et al and J.C. Dowdy and R.M. Sayre. J Clin Oncol. 2016;34:637-8.

7. Dugrand A, Olry A, Duval T, Hehn A, Froelicher Y, Bourgaud F. Coumarin and furanocoumarin quantitation in citrus peel via ultraperformance liquid chromatography coupled with mass spectrometry (UPLC-MS). J Agric Food Chem. 2013;61:10677-84.

8. Griffin AC, Hakim RE, Knox J. The wave length effect upon erythemal and carcinogenic response in psoralen treated mice. J Invest Dermatol. 1958;31:289-95.

9. Sun W, Rice MS, Park MK, Chun OK, Melough MM, Nan H, et al. Intake of Furocoumarins and Risk of Skin Cancer in 2 Prospective US Cohort Studies. J Nutr. 2020;

10. Parrish JA, Fitzpatrick TB, Tanenbaum L, Pathak MA. Photochemotherapy of psoriasis with oral methoxsalen and longwave ultraviolet light. N Engl J Med. 1974;291:1207-11.

11. Stern RS, PUVA Follow up Study. The risk of melanoma in association with long-term exposure to PUVA. J Am Acad Dermatol. 2001;44:755-61.

12. Stern RS, Nichols KT, Väkevä LH. Malignant melanoma in patients treated for psoriasis with methoxsalen (psoralen) and ultraviolet A radiation (PUVA). The PUVA Follow-Up Study. N Engl J Med. 1997;336:1041-5.

13. Alcalay J, Bucana C, Kripke ML. Cutaneous pigmented melanocytic tumor in a mouse treated with psoralen plus ultraviolet A radiation. Photodermatol Photoimmunol Photomed. 1990;7:28-31.

14. Sayre RM, Dowdy JC. The increase in melanoma: are dietary furocoumarins responsible? Med Hypotheses. 2008;70:855-9.

15. Riboli E, Hunt KJ, Slimani N, Ferrari P, Norat T, Fahey M, et al. European Prospective Investigation into Cancer and Nutrition (EPIC): study populations and data collection. Public Health Nutrition. 2002;5:1113-24.

16. Riboli E, Kaaks R. The EPIC Project: rationale and study design. European Prospective Investigation into Cancer and Nutrition. Int J Epidemiol. 1997;26 Suppl 1:S6-14. 
17. Margetts BM, Pietinen P. European Prospective Investigation into Cancer and Nutrition: validity studies on dietary assessment methods. Int J Epidemiol. 1997;26 Suppl 1:S1-5.

18. Cust AE, Smith BJ, Chau J, van der Ploeg HP, Friedenreich CM, Armstrong BK, et al. Validity and repeatability of the EPIC physical activity questionnaire: a validation study using accelerometers as an objective measure. Int J Behav Nutr Phys Act. 2008;5:33.

19. Caini S, Masala G, Saieva C, Kvaskoff M, Savoye I, Sacerdote C, et al. Coffee, tea and melanoma risk: findings from the European Prospective Investigation into Cancer and Nutrition. Int J Cancer. 2017;140:2246-55.

20. Fortes C, Mastroeni S, Melchi F, Pilla MA, Antonelli G, Camaioni D, et al. A protective effect of the Mediterranean diet for cutaneous melanoma. Int J Epidemiol. 2008;37:1018-29.

21. FAO. FAOSTAT, 2018; Citrus, http://faostat.fao.org/. Available from: http://www.fao.org/3/ai8092e.pdf

22. Mullen MP, Pathak MA, West JD, Harrist TJ, Dall'Acqua F. Carcinogenic effects of monofunctional and bifunctional furocoumarins. Natl Cancer Inst Monogr. 1984;66:205-10.

23. Cartwright LE, Walter JF. Psoralen-containing sunscreen is tumorigenic in hairless mice. J Am Acad Dermatol. 1983;8:830-6.

24. Wagstaff DJ. Dietary exposure to furocoumarins. Regulatory Toxicology and Pharmacology. 1991;14:261-72.

25. Guth S, Habermeyer M, Schrenk D, Eisenbrand G. Update of the toxicological assessment of furanocoumarins in foodstuffs (Update of the SKLM statement of 23/24 September 2004) - Opinion of the Senate Commission on Food Safety (SKLM) of the German Research Foundation (DFG). Molecular Nutrition \& Food Research. 55:807-10.

26. Dunnick JK, Forbes PD, Eustis SL, Hardisty JF, Goodman DG. Tumors of the skin in the HRA/Skh mouse after treatment with 8-methoxypsoralen and UVA radiation. Fundam Appl Toxicol. 1991;16:92-102.

27. Archier E, Devaux S, Castela E, Gallini A, Aubin F, Le Maître M, et al. Carcinogenic risks of psoralen UV-A therapy and narrowband UV-B therapy in chronic plaque psoriasis: a systematic literature review. J Eur Acad Dermatol Venereol. 2012;26 Suppl 3:22-31.

28. Stern RS, Liebman EJ, Väkevä L. Oral psoralen and ultraviolet-A light (PUVA) treatment of psoriasis and persistent risk of nonmelanoma skin cancer. PUVA Follow-up Study. J Natl Cancer Inst. 1998;90:1278-84.

29. Stern RS, Lunder EJ. Risk of squamous cell carcinoma and methoxsalen (psoralen) and UV-A radiation (PUVA). A meta-analysis. Arch Dermatol. 1998;134:1582-5.

30. Bickers DR, Pathak MA. Psoralen pharmacology: Studies on metabolism and enzyme induction. National Cancer Institute Monograph. 1984;MONOGR. 66:77-84.

31. Melough MM, Chun OK. Dietary furocoumarins and skin cancer: A review of current biological evidence. Food and Chemical Toxicology. 2018;122:163-71.

32. Scott BR, Pathak MA, Mohn GR. Molecular and genetic basis of furocoumarin reactions. Mutat Res. 1976;39:29-74. 
33. Derheimer FA, Hicks JK, Paulsen MT, Canman CE, Ljungman M. Psoralen-induced DNA interstrand cross-links block transcription and induce p53 in an ataxia-telangiectasia and rad3-relateddependent manner. Mol Pharmacol. 2009;75:599-607.

34. Laskin JD, Lee E, Yurkow EJ, Laskin DL, Gallo MA. A possible mechanism of psoralen phototoxicity not involving direct interaction with DNA. Proc Natl Acad Sci USA. 1985;82:6158-62.

35. Ortelli D, Edder P, Corvi C. Pesticide residues survey in citrus fruits. Food Addit Contam. $2005 ; 22: 423-8$.

36. Dennis LK, Lynch CF, Sandler DP, Alavanja MCR. Pesticide use and cutaneous melanoma in pesticide applicators in the agricultural heath study. Environ Health Perspect. 2010;118:812-7.

37. Parhiz H, Roohbakhsh A, Soltani F, Rezaee R, Iranshahi M. Antioxidant and anti-inflammatory properties of the citrus flavonoids hesperidin and hesperetin: an updated review of their molecular mechanisms and experimental models. Phytother Res. 2015;29:323-31.

38. Aune D, Giovannucci E, Boffetta P, Fadnes LT, Keum N, Norat T, et al. Fruit and vegetable intake and the risk of cardiovascular disease, total cancer and all-cause mortality-a systematic review and dose-response meta-analysis of prospective studies. Int J Epidemiol. 2017;46:1029-56.

39. Linseisen J, Rohrmann S, Miller AB, Bueno-de-Mesquita HB, Büchner FL, Vineis P, et al. Fruit and vegetable consumption and lung cancer risk: updated information from the European Prospective Investigation into Cancer and Nutrition (EPIC). Int J Cancer. 2007;121:1103-14.

40. Perez- Cornago A, Travis RC, Appleby PN, Tsilidis KK, Tjønneland A, Olsen A, et al. Fruit and vegetable intake and prostate cancer risk in the European Prospective Investigation into Cancer and Nutrition (EPIC). Int J Cancer. 2017;141:287-97.

41. Zamora-Ros R, Béraud V, Franceschi S, Cayssials V, Tsilidis KK, Boutron-Ruault M-C, et al. Consumption of fruits, vegetables and fruit juices and differentiated thyroid carcinoma risk in the European Prospective Investigation into Cancer and Nutrition (EPIC) study. Int J Cancer. 2018;142:449-59.

42. Chaudhary PR, Jayaprakasha GK, Patil BS. Ethylene degreening modulates health promoting phytochemicals in Rio Red grapefruit. Food Chemistry. 2015;188:77-83.

43. Chaudhary PR, Jayaprakasha GK, Porat R, Patil BS. Low temperature conditioning reduces chilling injury while maintaining quality and certain bioactive compounds of 'Star Ruby' grapefruit. Food Chemistry. 2014;153:243-9.

44. Gorgus E, Lohr C, Raquet N, Guth S, Schrenk D. Limettin and furocoumarins in beverages containing citrus juices or extracts. Food Chem Toxicol. 2010;48:93-8. 
Table 1: Cohort characteristics by country, European Prospective Investigation into Cancer and Nutrition (EPIC) cohort study ( $\mathrm{n}=476,160$ )

\begin{tabular}{|c|c|c|c|c|c|c|c|c|}
\hline & Cohort size & $\begin{array}{l}\text { Mean age at } \\
\text { recruitment }^{1}\end{array}$ & $\begin{array}{l}\text { Recruitment } \\
\text { period range }\end{array}$ & $\begin{array}{c}\text { Mean length of } \\
\text { follow-up }\end{array}$ & $\begin{array}{c}\text { Women } \\
(\%)\end{array}$ & $\begin{array}{l}\text { Total citrus intake } \\
(\mathrm{g} / \text { day })^{1}\end{array}$ & $\begin{array}{l}\text { Citrus fruit intake } \\
(\mathrm{g} / \text { day })^{1}\end{array}$ & $\begin{array}{c}\text { Citrus juice intake } \\
(\mathrm{g} / \text { day })^{1}\end{array}$ \\
\hline $\begin{array}{l}\text { Cohorts with available } \\
\text { data on citrus juice and } \\
\text { fruit intakes }\end{array}$ & 270,112 & $52.3(9.3)$ & 1991-1999 & $13.7(4.3)$ & 60.3 & $90.9(97.2)$ & $56.3(71.8)$ & $34.6(69.2)$ \\
\hline Italy & 39,592 & $50.5(7.9)$ & $1992-1998$ & $13.9(3.3)$ & 64.5 & 110.9 (102.9) & $84.7(83.0)$ & $26.1(52.4)$ \\
\hline The Netherlands & 36,539 & 48.9 (11.9) & 1994-1996 & $14.3(3.3)$ & 73.7 & $92.0(76.5)$ & $46.4(40.4)$ & $45.6(59.4)$ \\
\hline Germany & 48,557 & $50.5(8.5)$ & 1994-1998 & $10.4(3.2)$ & 56.4 & 82.4 (106.5) & $19.8(19.3)$ & $62.6(102.6)$ \\
\hline Denmark & 55,014 & $56.6(4.3)$ & 1993-1997 & $14.4(4.3)$ & 52.2 & $64.5(75.7)$ & $35.0(47.3)$ & $29.6(53.1)$ \\
\hline Sweden & 24,373 & $57.9(7.5)$ & 1991-1996 & $16.4(5.6)$ & 57.9 & 83.6 (100.9) & $33.2(35.3)$ & $50.5(92.4)$ \\
\hline France & 67,403 & $52.7(6.6)$ & 1993-1997 & $12.8(3.5)$ & 100 & - & $37.8(40.5)$ & - \\
\hline United Kingdom & 75,416 & $51.6(11.1)$ & 1993-2001 & $14.7(4.00)$ & 69.7 & - & $43.2(54.9)$ & - \\
\hline Norway & 33,975 & $48.3(4.3)$ & 1998 & $13.3(2.5)$ & 100 & - & $26.1(37.0)$ & - \\
\hline Naples & 4,953 & $50.5(7.3)$ & 1993-1997 & $15.0(2.6)$ & 100 & - & $87.8(62.2)$ & - \\
\hline Umea & 24,301 & $47.7(8.1)$ & 1992-1996 & $16.5(4.3)$ & 50.5 & - & $51.3(58.2)$ & - \\
\hline All & 476,160 & $52.0(8.5)$ & 1991-2001 & $13.8(4.1)$ & 70.1 & - & $49.5(63.7)$ & - \\
\hline
\end{tabular}

Abbreviation: SD, standard deviation

${ }^{1}$ Mean (SD) 
Table 2: Baseline characteristics of study participants according to quartile of total citrus intake, EPIC cohort $(n=270,112)$

\begin{tabular}{|c|c|c|c|c|}
\hline & Quartile 1 & Quartile 2 & Quartile 3 & Quartile 4 \\
\hline Participants (n) & 67,527 & 67,603 & 67,454 & 67,528 \\
\hline $\begin{array}{l}\text { Mean }(\mathrm{SD}) \text { of total citrus intake } \\
\text { (g/day) }\end{array}$ & $10.83(7.72)$ & $44.20(11.0)$ & $90.90(15.9)$ & $217.5(112.7)$ \\
\hline Women (\%) & 50.3 & 59.9 & 65.0 & 65.9 \\
\hline Age at recruitment (years) & $53.5(8.8)$ & $52.1(9.4)$ & $52.0(9.6)$ & $51.7(9.3)$ \\
\hline \multicolumn{5}{|l|}{ Body mass index, $\mathrm{kg} / \mathrm{m}^{2}(\%)$} \\
\hline$<18.5$ & 1.0 & 0.8 & 0.6 & 0.6 \\
\hline $18.5-24.9$ & 39.8 & 41.6 & 40.0 & 38.8 \\
\hline $25-29.9$ & 41.8 & 40.7 & 40.8 & 41.8 \\
\hline$\geq 30$ & 17.4 & 16.9 & 18.6 & 18.8 \\
\hline \multicolumn{5}{|l|}{ Education (\%) } \\
\hline None/primary & 43.0 & 37.2 & 41.6 & 41.7 \\
\hline Technical/secondary school & 38.8 & 40.8 & 38.3 & 37.2 \\
\hline University degree & 17.9 & 21.8 & 19.8 & 20.8 \\
\hline Unknown & 0.3 & 0.2 & 0.3 & 0.3 \\
\hline \multicolumn{5}{|l|}{ Smoking (\%) } \\
\hline Never smoker & 35.8 & 43.6 & 47.9 & 48.8 \\
\hline Former smoker & 28.8 & 28.7 & 26.8 & 26.4 \\
\hline Current smoker & 35.0 & 27.0 & 24.4 & 24.0 \\
\hline Unknown & 0.4 & 0.6 & 0.9 & 0.8 \\
\hline \multicolumn{5}{|l|}{ Alcohol intake, g/day (\%) } \\
\hline Non-consumer & 13.0 & 12.4 & 14.8 & 17.6 \\
\hline$>0-2.09$ & 14.2 & 16.3 & 18.1 & 17.8 \\
\hline $2.10-7.14$ & 16.5 & 18.5 & 18.6 & 18.6 \\
\hline $7.15-17.30$ & 22.4 & 23.6 & 22.5 & 21.4 \\
\hline$>17.31$ & 33.9 & 29.2 & 25.9 & 24.6 \\
\hline \multicolumn{5}{|l|}{ Physical activity (\%) } \\
\hline Inactive & 20.8 & 19.4 & 16.6 & 16.2 \\
\hline Moderately inactive & 30.6 & 27.4 & 25.4 & 25.4 \\
\hline Moderately active & 38.2 & 41.0 & 45.0 & 45.9 \\
\hline Active & 8.87 & 10.0 & 11.0 & 10.9 \\
\hline Missing & 1.57 & 2.3 & 2.0 & 1.6 \\
\hline Total energy intake $(\mathrm{kcal} / \mathrm{day})^{1}$ & $2085.4(632.2)$ & 2097.71 (619.9) & $2142.46(623.3)$ & $2259.5(659.2)$ \\
\hline Coffee $(g / \text { day })^{1}$ & $535.25(475.6)$ & $428.30(402.8)$ & $358.47(370.3)$ & $320.0(342.0)$ \\
\hline Vegetable (g/day) ${ }^{1}$ & 159.24 (115.9) & $181.14(128.5)$ & 215.99 (151.5) & $225.5(166.5)$ \\
\hline Citrus juice (g/day) ${ }^{1}$ & $3.12(4.4)$ & $13.10(15.0)$ & 28.27 (32.9) & $93.9(113.1)$ \\
\hline Citrus fruit $(g / \text { day })^{1}$ & $7.71(6.6)$ & $31.10(16.4)$ & $62.62(33.0)$ & $123.6(108.0)$ \\
\hline Non-citrus fruit (g/day) ${ }^{1}$ & $113.42(113.6)$ & $153.50(105.7)$ & $201.02(120.2)$ & $248.3(172.4)$ \\
\hline Non-citrus juice $(\mathrm{g} / \text { day })^{1}$ & $18.71(74.1)$ & $28.99(75.9)$ & $32.17(75.2)$ & $45.6(108.3)$ \\
\hline
\end{tabular}

Abbreviations: EPIC, European Prospective Investigation into Cancer and Nutrition; SD, standard deviation

${ }^{1}$ Mean (SD) 
Table 3: Hazard ratios (HRs) and 95\% confidence intervals (Cls) for intake of total citrus and risk of skin cancer, EPIC cohort $(n=270,112)$

\section{Total citrus intake}

\begin{tabular}{|c|c|c|c|c|c|}
\hline & & \multirow[b]{2}{*}{ P-trend } \\
\hline & Quartile 1 & Quartile 2 & Quartile 3 & Quartile 4 & \\
\hline $\mathrm{N}$ & 67,527 & 67,603 & 67,454 & 67,528 & \\
\hline Mean (g/day) & 10.8 & 44.2 & 90.9 & 217.5 & \\
\hline \multicolumn{6}{|l|}{ Skin cancer } \\
\hline No cases & 2,586 & 2,119 & 1,955 & 1,788 & \\
\hline Age-adjusted HR (95\% Cl) & 1 (ref) & $1.11(1.05-1.18)$ & $1.17(1.10-1.25)$ & $1.17(1.10-1.24)$ & $<.0001$ \\
\hline Multivariable-adjusted $\mathrm{HR}^{1}(95 \% \mathrm{Cl})$ & 1 (ref) & $1.08(1.02-1.15)$ & $1.13(1.06-1.20)$ & $1.12(1.05-1.19)$ & 0.0001 \\
\hline Multivariable-adjusted $\mathrm{HR}^{2}(95 \% \mathrm{Cl})$ & 1 (ref) & $1.07(1.01-1.13)$ & $1.11(1.04-1.19)$ & $1.10(1.03-1.18)$ & 0.001 \\
\hline \multicolumn{6}{|l|}{ Melanoma } \\
\hline No cases & 395 & 340 & 323 & 313 & \\
\hline Age-adjusted HR (95\% Cl) & 1 (ref) & $1.01(0.87-1.17)$ & $1.09(0.94-1.27)$ & $1.04(0.89-1.21)$ & 0.44 \\
\hline Multivariable-adjusted $\mathrm{HR}^{1}(95 \% \mathrm{Cl})$ & 1 (ref) & $0.98(0.85-1.14)$ & $1.05(0.90-1.23)$ & $1.00(0.85-1.17)$ & 0.78 \\
\hline Multivariable-adjusted $\mathrm{HR}^{2}(95 \% \mathrm{Cl})$ & 1 (ref) & $0.97(0.83-1.13)$ & $1.03(0.88-1.21)$ & $0.98(0.83-1.15)$ & 0.96 \\
\hline \multicolumn{6}{|l|}{ BCC } \\
\hline No cases & 1,797 & 1,416 & 1,290 & 1,101 & \\
\hline Age-adjusted HR $(95 \% \mathrm{Cl})$ & 1 (ref) & $1.12(1.05-1.21)$ & $1.17(1.09-1.26)$ & $1.17(1.08-1.27)$ & $<.0001$ \\
\hline Multivariable-adjusted $\mathrm{HR}^{1}(95 \% \mathrm{Cl})$ & 1 (ref) & $1.09(1.01-1.17)$ & $1.12(1.05-1.21)$ & $1.12(1.03-1.21)$ & 0.001 \\
\hline Multivariable-adjusted $\mathrm{HR}^{2}$ (95\% Cl) & 1 (ref) & $1.08(1.00-1.16)$ & $1.11(1.03-1.20)$ & $1.11(1.02-1.20)$ & 0.007 \\
\hline \multicolumn{6}{|l|}{ SCC } \\
\hline No cases & 312 & 282 & 262 & 309 & \\
\hline Age-adjusted HR $(95 \% \mathrm{Cl})$ & 1 (ref) & $1.14(0.97-1.34)$ & $1.21(1.02-1.44)$ & $1.28(1.09-1.51)$ & 0.002 \\
\hline Multivariable-adjusted $\mathrm{HR}^{1}(95 \% \mathrm{Cl})$ & 1 (ref) & $1.12(0.95-1.32)$ & $1.18(1.00-1.41)$ & $1.25(1.06-1.48)$ & 0.007 \\
\hline Multivariable-adjusted $\mathrm{HR}^{2}$ (95\% Cl) & 1 (ref) & $1.11(0.94-1.31)$ & $1.17(0.98-1.39)$ & $1.23(1.04-1.47)$ & 0.01 \\
\hline
\end{tabular}

Abbreviations: $\mathrm{BCC}$, basal-cell carcinoma; $\mathrm{Cl}$, confidence intervals; EPIC, European Prospective Investigation into Cancer and Nutrition; HR, hazard ratio; SCC, squamous-cell carcinoma

Age-adjusted: adjusted for age and stratified by study center, sex, and age at recruitment

${ }^{1}$ Stratified by study center, sex, age at recruitment, and adjusted for education (none, primary school, technical/professional school, secondary school, university or higher degree), body mass index (BMI; $<25,25-$ 29 , or $\geq 30 \mathrm{~kg} / \mathrm{m}^{2}$ ), smoking (never, former, and current), alcohol intake (non-consumer, then categorized in quartiles, g per day), physical activity (metabolic equivalent of task [MET] hour/week), and energy intake (continuous)

${ }^{2}$ Additionally adjusted for total vegetable intake (tertiles), coffee intake (tertiles), non-citrus fruit intake (tertiles), and non-citrus juice intake (tertiles). Phomogeneity for total citrus and skin cancer type was 0.14 ssss 
Table 4: Hazard ratios (HRs) and 95\% confidence intervals (Cls) for intake of citrus fruit and risk of skin cancer, EPIC cohort $(n=270,112)$

\begin{tabular}{|c|c|c|c|c|c|}
\hline & \multicolumn{4}{|c|}{ Citrus fruit intake } & \multirow[b]{2}{*}{ P-trenc } \\
\hline & Quartile 1 & Quartile 2 & Quartile 3 & Quartile 4 & \\
\hline $\mathrm{N}$ & 67,297 & 67,756 & 67,531 & 67,528 & \\
\hline Mean (g/day) & 4.4 & 20.2 & 52.8 & 147.5 & \\
\hline \multicolumn{6}{|l|}{ Skin cancer } \\
\hline No cases & 2,540 & 1,968 & 2,126 & 1,814 & \\
\hline Age-adjusted HR $(95 \% \mathrm{Cl})$ & 1 (ref) & $1.08(1.02-1.15)$ & $1.14(1.07-1.21)$ & $1.15(1.08-1.23)$ & $<.0001$ \\
\hline Multivariable-adjusted $\mathrm{HR}^{1}(95 \% \mathrm{Cl})$ & 1 (ref) & $1.04(0.98-1.11)$ & $1.10(1.04-1.17)$ & $1.12(1.04-1.19)$ & 0.0003 \\
\hline Multivariable-adjusted $\mathrm{HR}^{2}(95 \% \mathrm{Cl})$ & 1 (ref) & $1.03(0.97-1.09)$ & $1.07(1.01-1.15)$ & $1.08(1.01-1.16)$ & 0.01 \\
\hline \multicolumn{6}{|l|}{ Melanoma } \\
\hline No cases & 360 & 359 & 364 & 288 & \\
\hline Age-adjusted HR $(95 \% \mathrm{Cl})$ & 1 (ref) & $1.07(0.92-1.24)$ & $1.20(1.03-1.39)$ & $1.27(1.07-1.51)$ & 0.002 \\
\hline Multivariable-adjusted $\mathrm{HR}^{1}(95 \% \mathrm{Cl})$ & 1 (ref) & $1.04(0.90-1.21)$ & $1.16(1.00-1.36)$ & $1.24(1.04-1.47)$ & 0.007 \\
\hline Multivariable-adjusted $\mathrm{HR}^{2}(95 \% \mathrm{Cl})$ & 1 (ref) & $1.05(0.90-1.22)$ & $1.17(0.99-1.37)$ & $1.23(1.02-1.48)$ & 0.01 \\
\hline \multicolumn{6}{|l|}{ BCC } \\
\hline No cases & 1,817 & 1,213 & 1,372 & 1,202 & \\
\hline Age-adjusted HR $(95 \% \mathrm{Cl})$ & 1 (ref) & $1.06(0.98-1.14)$ & $1.13(1.05-1.21)$ & $1.10(1.01-1.19)$ & 0.003 \\
\hline Multivariable-adjusted HR ${ }^{1}(95 \% \mathrm{Cl})$ & 1 (ref) & $1.01(0.94-1.09)$ & $1.09(1.01-1.17)$ & $1.06(0.97-1.15)$ & 0.06 \\
\hline Multivariable-adjusted $\mathrm{HR}^{2}(95 \% \mathrm{Cl})$ & 1 (ref) & $0.99(0.92-1.07)$ & $1.05(0.98-1.14)$ & $1.02(0.94-1.11)$ & 0.37 \\
\hline \multicolumn{6}{|l|}{ ScC } \\
\hline No cases & 282 & 332 & 297 & 254 & \\
\hline Age-adjusted HR $(95 \% \mathrm{Cl})$ & 1 (ref) & $1.24(1.05-1.46)$ & $1.11(0.93-1.31)$ & $1.33(1.10-1.60)$ & 0.01 \\
\hline Multivariable-adjusted $\mathrm{HR}^{1}(95 \% \mathrm{Cl})$ & 1 (ref) & $1.22(1.03-1.43)$ & $1.08(0.91-1.29)$ & $1.30(1.08-1.57)$ & 0.03 \\
\hline Multivariable-adjusted $\mathrm{HR}^{2}(95 \% \mathrm{Cl})$ & 1 (ref) & $1.18(1.00-1.40)$ & $1.05(0.88-1.25)$ & $1.26(1.03-1.54)$ & 0.10 \\
\hline
\end{tabular}

Abbreviations: $\mathrm{BCC}$, basal-cell carcinoma; $\mathrm{Cl}$, confidence intervals; EPIC, European Prospective Investigation into Cancer and Nutrition; HR, hazard ratio; SCC, squamous-cell carcinoma

Age-adjusted: adjusted for age and stratified by study center, sex, and age at recruitment

${ }^{1}$ Stratified by study center, sex, age at recruitment, and adjusted for education (none, primary school, technical/professional school, secondary school, university or higher degree), body mass index (BMI; $<25,25-$ 29 , or $\geq 30 \mathrm{~kg} / \mathrm{m}^{2}$ ), smoking (never, former, and current), alcohol intake (non-consumer, then categorized in quartiles, g per day), physical activity (metabolic equivalent of task [MET] hour/week), and energy intake (continuous)

${ }^{2}$ Additionally adjusted for total vegetable intake (tertiles), non-citrus fruits (tertiles), citrus juice (tertiles) and coffee intake (tertiles). Phomogeneity for citrus fruit and skin cancer type was 0.21 . 
Table 5: Hazard ratios (HRs) and 95\% confidence intervals (Cls) for intake of citrus juice and risk of skin cancer, EPIC cohort $(n=270,112)$

\begin{tabular}{|c|c|c|c|c|c|}
\hline & \multicolumn{4}{|c|}{ Citrus juice intake } & \multirow[b]{2}{*}{ P-trend } \\
\hline & Quartile 1 & Quartile 2 & Quartile 3 & Quartile 4 & \\
\hline $\mathrm{N}$ & 67,364 & 67,692 & 67,268 & 67,788 & \\
\hline Mean (g/day) & 0.01 & 2.8 & 17.6 & 117.7 & \\
\hline \multicolumn{6}{|l|}{ Skin cancer } \\
\hline No cases & 2,089 & 1,725 & 2,154 & 2,480 & \\
\hline Age-adjusted HR $(95 \% \mathrm{Cl})$ & 1 (ref) & $1.03(0.96-1.10)$ & $1.10(1.03-1.17)$ & $1.16(1.09-1.23)$ & $<.0001$ \\
\hline Multivariable-adjusted $\mathrm{HR}^{1}(95 \% \mathrm{Cl})$ & 1 (ref) & $0.99(0.93-1.06)$ & $1.04(0.98-1.12)$ & $1.09(1.02-1.16)$ & 0.002 \\
\hline Multivariable-adjusted $\mathrm{HR}^{2}(95 \% \mathrm{Cl})$ & 1 (ref) & $0.99(0.92-1.06)$ & $1.04(0.97-1.11)$ & $1.08(1.02-1.16)$ & 0.004 \\
\hline \multicolumn{6}{|l|}{ Melanoma } \\
\hline No cases & 395 & 255 & 349 & 372 & \\
\hline Age-adjusted HR $(95 \% \mathrm{Cl})$ & 1 (ref) & $1.04(0.87-1.23)$ & $1.07(0.92-1.26)$ & $0.96(0.83-1.12)$ & 0.64 \\
\hline Multivariable-adjusted $\mathrm{HR}^{1}(95 \% \mathrm{Cl})$ & 1 (ref) & $1.01(0.85-1.20)$ & $1.03(0.88-1.21)$ & $0.92(0.79-1.07)$ & 0.30 \\
\hline Multivariable-adjusted $\mathrm{HR}^{2}(95 \% \mathrm{Cl})$ & 1 (ref) & $1.01(0.84-1.21)$ & $1.03(0.87-1.22)$ & $0.92(0.78-1.08)$ & 0.31 \\
\hline \multicolumn{6}{|l|}{ BCC } \\
\hline No cases & 1,244 & 1,225 & 1,501 & 1,634 & \\
\hline Age-adjusted HR $(95 \% \mathrm{Cl})$ & 1 (ref) & $1.03(0.95-1.12)$ & $1.10(1.02-1.20)$ & $1.19(1.10-1.29)$ & $<.0001$ \\
\hline Multivariable-adjusted $\mathrm{HR}^{1}(95 \% \mathrm{Cl})$ & 1 (ref) & $0.99(0.91-1.07)$ & $1.04(0.96-1.13)$ & $1.11(1.02-1.20)$ & 0.004 \\
\hline Multivariable-adjusted $\mathrm{HR}^{2}(95 \% \mathrm{Cl})$ & 1 (ref) & $0.99(0.91-1.07)$ & $1.04(0.95-1.13)$ & $1.10(1.01-1.19)$ & 0.008 \\
\hline \multicolumn{6}{|l|}{ SCC } \\
\hline No cases & 362 & 179 & 237 & 387 & \\
\hline Age-adjusted HR $(95 \% \mathrm{Cl})$ & 1 (ref) & $1.01(0.84-1.22)$ & $1.20(1.00-1.43)$ & $1.29(1.11-1.50)$ & 0.0004 \\
\hline Multivariable-adjusted $\mathrm{HR}^{1}(95 \% \mathrm{Cl})$ & 1 (ref) & $0.98(0.81-1.19)$ & $1.16(0.97-1.39)$ & $1.25(1.07-1.46)$ & 0.001 \\
\hline Multivariable-adjusted $\mathrm{HR}^{2}$ (95\% Cl) & 1 (ref) & $0.95(0.78-1.16)$ & $1.11(0.92-1.35)$ & $1.23(1.05-1.44)$ & 0.004 \\
\hline
\end{tabular}

Abbreviations: $\mathrm{BCC}$, basal-cell carcinoma; $\mathrm{Cl}$, confidence intervals; EPIC, European Prospective Investigation into Cancer and Nutrition; HR, hazard ratio; SCC, squamous-cell carcinoma

Age-adjusted: adjusted for age and stratified by study center, sex, and age at recruitment

${ }^{1}$ Stratified by study center, sex, age at recruitment, and adjusted for education (none, primary school, technical/professional school, secondary school, university or higher degree), body mass index (BMI; <25, 2529 , or $\geq 30 \mathrm{~kg} / \mathrm{m}^{2}$ ), smoking (never, former, and current), alcohol intake (non-consumer, then categorized in quartiles, g per day), physical activity (metabolic equivalent of task [MET] hour/week), and energy intake (continuous).

${ }^{2}$ Additionally adjusted for total vegetable intake (tertiles), citrus fruit (tertiles), non-citrus juice (tertiles) and coffee intake (tertiles). Phomogeneity for citrus juice and skin cancer type was 0.02 